\title{
INFLUÊNCIA ANTRÓPICA E DA PRECIPITAÇÃO NA DISTRIBUIÇÃO ESPAÇO-TEMPORAL DE FOCOS DE CALOR NA MICRORREGIÃO DE PARAGOMINAS, PARÁ
}

\author{
CUNHA NETO, Ernandes Macedo da - netomacedo878@gmail.com \\ Universidade Federal do Paraná/ UFPR
}
BEZERRA, Jade Cristynne Franco - jadefranco9@gmail.com Universidade Federal do Paraná/ UFPR
MELO, Márcio Roberto da Silva - mrsmelo@yahoo.com.br Universidade Federal Rural da Amazônia / UFRA
SANTOS, Núbia de Fátima Alves dos - nubia.santos@ufra.edu.br Universidade Federal Rural da Amazônia / UFRA
BORGES, Luciana da Silva - luciana.borges@ufra.edu.br Universidade Federal Rural da Amazônia / UFRA

Submetido em: $24 / 07 / 2020$

Aceito para publicação em: 17/02/2021

Publicado em: 06/04/2021

DOI: http://dx.doi.org/10.5380/abclima.v28i0.75438

\begin{abstract}
RESUMO: A Amazônia legal obteve uma média de 156.729 focos de calor entre os anos de 2000-2017, destes cerca de $22 \%$ se concentram no estado do Pará. Assim, o objetivo desse trabalho foi analisar a dinâmica espaço-temporal dos focos de calor na microrregião de Paragominas/PA. Os dados de focos de calor foram adquiridos no banco de dados do INPE, estes foram analisados num período de 15 anos, englobando os anos de 2002 a 2017. Estes dados foram comparados com a precipitação, desmatamento e expansão agrícola. A maior incidência dos focos de calor é no período seco, com incremento médio de $2830 \%$ em relação ao chuvoso. Essa variável reduz cerca de $68 \%$ entre esses períodos. Há diminuição de $94 \%$ do desmatamento e crescimento de $599131 \%$ das áreas de agricultura. A concentração dos focos de calor obedece a orientação Norte/Sul da microrregião, nos entornos das rodovias, áreas desmatadas e de agricultura, bem como programas de assentamento. O padrão espacial dos focos de calor da microrregião de Paragominas é influenciado pela sazonalidade da precipitação, havendo uma maior concentração destes no centro da microrregião, sob orientação Norte/Sul, onde estão as áreas de menor precipitação. O padrão temporal e a intensidade dos focos de calor são influenciados pela ação antrópica, coincidindo com as áreas de menor precipitação, devido a associação do uso do fogo com o período de estiagem, bem como a agricultura anual.
\end{abstract}

PALAVRAS-CHAVE: Amazônia; Agricultura; Desmatamento; Fogo; Queimadas.

ANTROPHIC AND PRECIPITATION INFLUENCE ON ACTIVE FIRE SPATIO-TEMPORAL DISTRIBUTION IN PARAGOMINAS MICROREGION, PARÁ

ABSTRACT: The legal Amazon obtained an average of 126,938 active fire between the years 1998-2018, of which about 32,934 are concentrated in the state of Pará. The objective of this study was to analyze the spatial-temporal dynamics of hot spots in the Paragominas microregion. The active fire data were acquired in the INPE database, these were analyzed over a period of 15 years, covering the years 2002 to 2017 . These data were compared with precipitation, deforestation and agricultural expansion. The highest incidence of heat sources is in the dry period, with an average increase of $28303 \%$ in relation to the rainy period. Rainfall reduces about $68 \%$ between these periods. There is 
a $94 \%$ reduction in deforestation and $599131 \%$ growth in agriculture. The concentration of active fire follows the North/South orientation of the microregion, in the surroundings of roads, deforested areas and agriculture, as well as settlement programs. The actie fire's spatial pattern in the Paragominas micro-region is affected by the rainfall seasonality, occurring a highest concentration at the micro-region's center, in a north/south orientation, where the rainfall is lower. The temporal pattern and the intensity of the active fire are affected by anthropic action, which coincides with the lowest rainfall areas, given the fire use involvement in the dry season, and the seasonal agriculture.

KEYWORDS: Amazon; Agriculture; Deforestation; Fire; Wildfires.

\section{INTRODUÇÃo}

Nos últimos anos, a preocupação com os riscos de queimadas no Brasil tem-se acentuado, especialmente em ecossistemas florestais como o da Floresta Amazônica, por se tratar de um dos principais causadores de alterações na paisagem, bem como inúmeros danos ao meio ambiente, a exemplo das perdas de espécies da fauna e da flora, alterações nas propriedades físico-químicas e biológicas do solo, além de contribuir para o aumento das emissões de gases do efeito estufa, e consequentemente, mudanças climáticas (ABREU; SOUZA, 2016; BITTENCOURT; BAZZAN; LAHM, 2013; CARVALHO; CARDOSO; ALMEIDA, 2016; CAÚlA et al., 2015; CLEMENTE; OLIVEIRA JÚNIOR; LOUZADA, 2017).

De maneira geral, embora seja possível a ocorrência de focos de calor por condições naturais (FERNANDES et al., 2011), são as intervenções humanas as principais causadoras das queimadas no país (CLEMENTE; OLIVEIRA JÚNIOR; LOUZADA, 2017; NASCIMENTO et al., 2017; SANTOS et al., 2019). No bioma amazônico, assim como boa parte do território brasileiro, as queimadas estão diretamente associadas às práticas rudimentares de preparo e limpeza de área subsequentes, em muitos casos, de desmatamento, com o propósito de atender à crescente demanda por terras destinadas às atividades agropecuárias (CAÚLA et al., 2015; LOPES et al., 2017).

Outro aspecto importante diz respeito aos efeitos do clima sobre a ocorrência e propagação do fogo. Segundo Nunes; Soares; Batista (2007) e Torres et al. (2011), elementos como a temperatura do ar, umidade relativa e a precipitação pluviométrica influenciam significativamente nas proporções das queimadas, ou seja, em longos períodos de estiagem, com baixos índices pluviométricos e baixa umidade, o ambiente torna-se mais seco, ocasionando a evapotranspiração excessiva da vegetação (LARCHER, 2000), tornando a biomassa presente na superfície mais seca e, consequentemente, mais vulnerável a ocorrência e a propagação de fogo (DEPPE et al., 2004; GOIS et al., 2016; NEPSTAD et al., 2007). Em contrapartida, em períodos chuvosos, há uma redução drástica nos registros de focos de calor.

Contudo, vale ressaltar que em condições climáticas que estejam sob efeito do fenômeno ENOS (El Niño Oscilação Sul), esses fatores podem ser potencializados, favorecendo a ocorrência e o alastramento dessas queimadas (ALMEIDA et al., 2017; CAÚLA et al., 2017; COELHO JUNIOR; MARTINS; CARVALHO, 2018). No estado do Pará, o período seco caracteriza-se por apresentar precipitação mensal média com valores inferiores a $50 \mathrm{~mm}$. mês ${ }^{-1}$, de tal maneira que as chuvas desse período são isoladas e esparsas (SOUZA; AMBRIZZI, 2003). 
A relação de crescimento inverso existente entre o regime pluviométrico com os registros de focos de calor pode ser observada em diversos trabalhos (CLEMENTE; OLIVEIRA JÚNIOR; LOUZADA, 2017; NASCIMENTO et al., 2017; SANTOS et al., 2019). No entanto, ainda se faz necessário averiguar a distribuição espacial das chuvas e seu efeito sobre a ocorrência de focos de calor, a fim de identificar áreas mais vulnerais a ocorrência de queimadas. De acordo com Carvalho; Assad; Pinto (2012) informações precisas sobre a distribuição espacial das chuvas são de fundamental importância tanto para o planejamento agrícola como para questões ambientais.

Neste sentido, o uso de técnicas de sensoriamento remoto e geoprocessamento tem se mostrado eficazes no monitoramento de queimadas, devido à sua agilidade e praticidade, tornando-se primordial para a prevenção e controle de incêndio em áreas de vegetação (SYPHARD; KEELEY; BRENNAN, 2011; TOMZHINSKI; COURA; FERNANDES, 2011). É por meio de imagens, obtidas por sensores remotos acoplados em satélites, que o Instituto Nacional de Pesquisas Espaciais - INPE detecta e localiza focos de calor, ou seja, pontos da superfície terrestre que apresentam temperatura de brilho maiores ou iguais a $47^{\circ} \mathrm{C}$, bem como avalia seu comportamento no espaço e no tempo.

De acordo com dados do INPE, entre os anos de 2000 a 2017, a Amazônia legal obteve 2.821.133 focos de calor, sendo que destes cerca de $22 \%$ se concentraram no estado do Pará (INPE, 2020a), com destaque para a microrregião de Paragominas, localizada na região nordeste estado, a qual, neste intervalo, passou por um processo intenso de alterações em sua paisagem, em função da expansão da agricultura, pecuária e silvicultura.

Dentre as inúmeras ferramentas, o algoritmo estimador de densidade de Kernel é um dos métodos de geoprocessamento empregados para estudar a distribuição espacial dos focos de calor, pois permite observar quais as áreas de maior incidência destes (SYPHARD; KEELEY; BRENNAN, 2011; THOMPSON et al., 2011; TOMZHINSKI; COURA; FERNANDES, 2011). Da mesma forma, métodos de interpolação geoestatística, a exemplo da krigagem, são considerados excelentes estimadores em estudo voltados a análise da distribuição espacial de precipitação pluviométrica (MACHADO et al., 2010). Neste contexto, objetivou-se com este trabalho analisar a dinâmica espaçotemporal dos focos de calor na microrregião de Paragominas, estado do Pará, por meio técnicas de geoprocessamento.

\section{MATERIAL E MÉTODOS}

\subsection{DESCRIÇÃO DA ÁREA DE ESTUDO}

A microrregião de Paragominas (Figura 1) está localizada na mesorregião Sudeste Paraense e é composta por sete municípios, são eles: Abel Figueiredo, Bom Jesus do Tocantins, Dom Elizeu, Goianésia do Pará, Paragominas, Rondon do Pará e Ulianópolis. O ponto central da área de estudo está entre as coordenadas geográficas 350'22,598"S e 47054'43,57"O.

A microrregião possui o clima do tipo "Aw", segundo a classificação climática de Köppen, com temperatura e umidade do ar assumindo valores médios de $26,3^{\circ} \mathrm{C}$ e $81 \%$, respectivamente, enquanto a precipitação média é de $1800 \mathrm{~mm} . \mathrm{ano}^{-1}$ (ALVARES et al., 2013). Neste local há dois períodos climáticos: 
chuvoso e seco, sendo o chuvoso compreendendo os meses de janeiro até junho, e o seco, de julho a dezembro. A economia da região é baseada, principalmente na agricultura e na pecuária, sobretudo nos municípios de Paragominas, Ulianópolis e Dom Eliseu, onde a agricultura anual possui forte ligação com a economia local, enquanto nos demais municípios destaca-se a criação de gado (PENA; OLIVEIRA; CAMPOS, 2011).

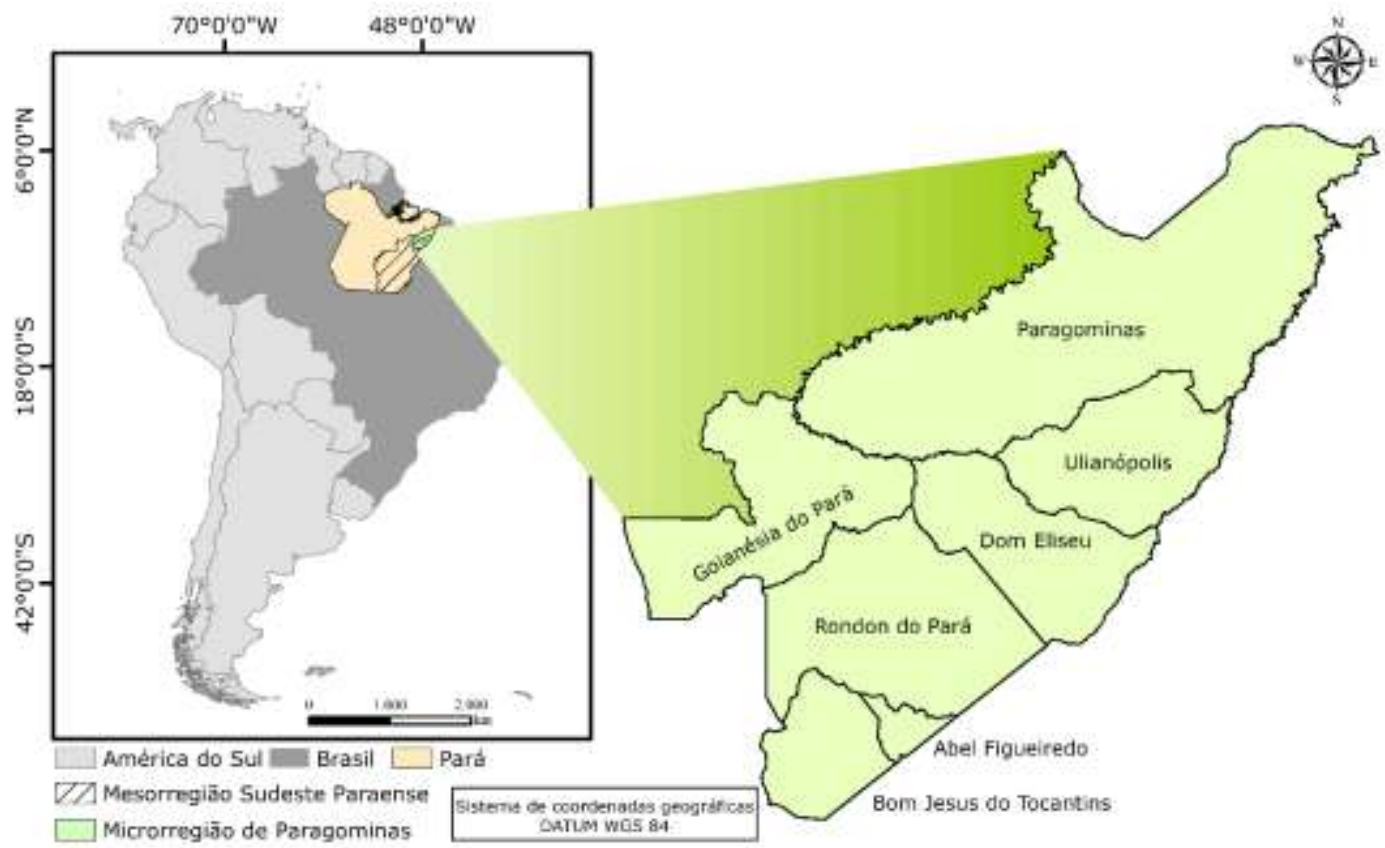

Figura 1 - Localização da microrregião de Paragominas, estado do Pará.

\subsection{AQUISIÇÃO DOS DADOS}

Os dados de focos de calor foram obtidos no banco de dados do Instituto Nacional de Pesquisas Espaciais, a partir do programa Queimadas (INPE, 2020b), os dados estão disponíveis em <http://www.inpe.br/queimadas>. Com vistas em esclarecer a dinâmica dos focos de calor foram obtidos dados de expansão da fronteira agrícola, no portal MAPBIOMAS (MAPBIOMAS DEVELOPMENT TEAM, 2019), bem como desmatamento do Projeto de Monitoramento do Desmatamento na Amazônia Legal por Satélite (PRODES) (INPE, 2019). Além disso, com o mesmo propósito foram utilizados os dados de precipitação anual adquiridos no Centro Europeu de Previsões Meteorológica a Médio Prazo - ECMWF (ECMWF, 2020).

\subsection{PROCESSAMENTO DOS DADOS}

Foram analisados os focos de calor num período de 15 anos, englobando os anos de 2002 a 2017. Foi realizada uma análise multitemporal em um intervalo de três em três anos. Estes dados dos focos de calor foram submetidos ao estimador de densidade Kernel, com auxílio do software QGIS versão 2.18 (QGIS DEVELOPMENT TEAM, 2016), a fim de observar o comportamento dos 
focos de calor na microrregião, de modo que o mapa de Kernel foi classificado nas seguintes classes: nulo, baixo, moderado, alto, muito alto e extremo.

O estimador de densidade Kernel é uma técnica que estima a intensidade padrão espacial de pontos na superfície estudada, de modo que essa ferramenta desenha uma vizinhança circular ao redor de cada ponto da amostra, correspondendo ao raio de influência (OLIVEIRA; DE OLIVEIRA, 2017; TONINI et al., 2016).

A partir do banco de dados de precipitação anual, foi possível zonear as áreas com diferentes índices pluviométricos a partir da interpolação por krigagem ordinária por meio da ferramenta SAGAGIS do software QGIS versão 2.18. Sabe-se que a mesorregião Sudeste Paraense, a qual pertence a microrregião de Paragominas, possui dois períodos climáticos: seco e chuvoso, assim, os dados de precipitação foram separados neste período, a fim de verificar a influência da precipitação na incidência dos focos de calor.

Além disso, os dados do PRODES e MAPBIOMAS foram cruzados com os focos de calor para observar se há influência do desmatamento e expansão agrícola na ocorrência dos focos de calor.

\section{RESULTADOS E DISCUSSÃO}

De acordo com os dados do INPE, entre os anos de 2002 e 2017, foram contabilizados 280.767 focos de calor na microrregião de Paragominas. Os anos de 2003 e 2015 foram os que registraram a menor e maior ocorrência de focos, respectivamente, apresentando uma amplitude quantitativa de mais de 56 mil focos de calor (Tabela 1).

Em relação a precipitação pluviométrica, foi observado uma média anual de 1936 mm, sendo 2006 e 2010, os anos com os maiores e menores volumes acumulados, $2377 \mathrm{~mm}$ e $1458 \mathrm{~mm}$, respectivamente (Tabela 1).

Tabela 1 - Focos de calor e precipitação média anual por período climático da microrregião de Paragominas, Pará, Brasil.

\begin{tabular}{ccccccccccc}
\hline \multirow{2}{*}{ Ano } & \multicolumn{3}{c}{ Total } & \multicolumn{2}{c}{ Chuvoso } & \multicolumn{2}{c}{ Seco } & \multicolumn{2}{c}{ Tx (\%) } & \multirow{2}{*}{ ENOS } \\
\cline { 2 - 9 } & Fct & Ppt & Fcc & Ppc & Fcs & Pps & Tfc & Tpp & \\
\hline 2002 & 5012 & 2367,85 & 91 & 1683,85 & 4921 & 648,77 & 5307,69 & $-61,47$ & El Niño \\
2003 & 2892 & 2263,69 & 194 & 1519,33 & 2698 & 702,05 & 1290,72 & $-53,79$ & El Niño \\
2004 & 20049 & 2375,87 & 1051 & 1692,30 & 18998 & 680,84 & 1707,61 & $-59,77$ & Normal \\
2005 & 17853 & 1815,64 & 1826 & 1151,77 & 16027 & 635,77 & 777,71 & $-44,80$ & Normal \\
2006 & 11468 & 2377,95 & 929 & 1810,70 & 10539 & 533,79 & 1034,45 & $-70,52$ & El Niño \\
2007 & 17446 & 2032,15 & 862 & 1327,13 & 16584 & 676,51 & 1823,90 & $-49,02$ & La Niña \\
2008 & 10713 & 1736,07 & 232 & 1434,90 & 10481 & 285,77 & 4417,67 & $-80,08$ & La Niña \\
2009 & 11147 & 2157,13 & 220 & 1863,51 & 10927 & 356,03 & 4866,82 & $-80,89$ & El Niño \\
2010 & 8852 & 1458,21 & 566 & 985,93 & 8286 & 403,93 & 1363,96 & $-59,03$ & El Niño \\
2011 & 6329 & 2018,79 & 134 & 1689,25 & 6195 & 354,31 & 4523,13 & $-79,03$ & La Niña \\
2012 & 14093 & 1470,52 & 373 & 1162,34 & 13720 & 276,38 & 3578,28 & $-76,22$ & Normal \\
2013 & 4997 & 1677,77 & 232 & 1030,52 & 4765 & 328,71 & 1953,88 & $-68,10$ & Normal
\end{tabular}




\begin{tabular}{cccccccccc}
2014 & 12070 & 2008,93 & 228 & 1661,87 & 11842 & 294,20 & 5093,86 & $-82,30$ & Normal \\
2015 & 59685 & 1482,43 & 1569 & 1319,23 & 58116 & 161,95 & 3604,02 & $-87,72$ & El Niño \\
2016 & 22721 & 1483,20 & 3661 & 1067,98 & 19060 & 401,28 & 420,62 & $-62,43$ & El Niño \\
2017 & 55440 & 2264,63 & 1488 & 1880,36 & 53952 & 384,28 & 3525,81 & $-79,56$ & La Niña \\
\hline
\end{tabular}

Onde: Fct $=$ focos de calor total; Ppt $=$ precipitação média anual; Fcc $=$ focos de calor do período chuvoso; $\mathrm{Ppc}=$ precipitação média do período chuvoso; $\mathrm{Fcs}=$ focos de calor do período seco; Pps = precipitação média do período seco; $\mathrm{Tx}=$ taxa de crescimento; $\mathrm{Tfc}=$ taxa de crescimento dos focos de calor entre o período chuvoso e seco; Tpp = taxa de crescimento da precipitação entre o período chuvoso e seco.

A análise da relação interanual entre focos de calor e a precipitação média anual (Figura 2a), apontou para uma tendência de redução da precipitação média anual, em torno de $4,36 \%$, e tendência de aumento para os registros de focos na microrregião de 1006,15\%, entre os anos de 2002 e 2017. Contudo, a oscilação quantitativa de focos não possibilitou uma associação direta entre as variáveis em escala temporal.

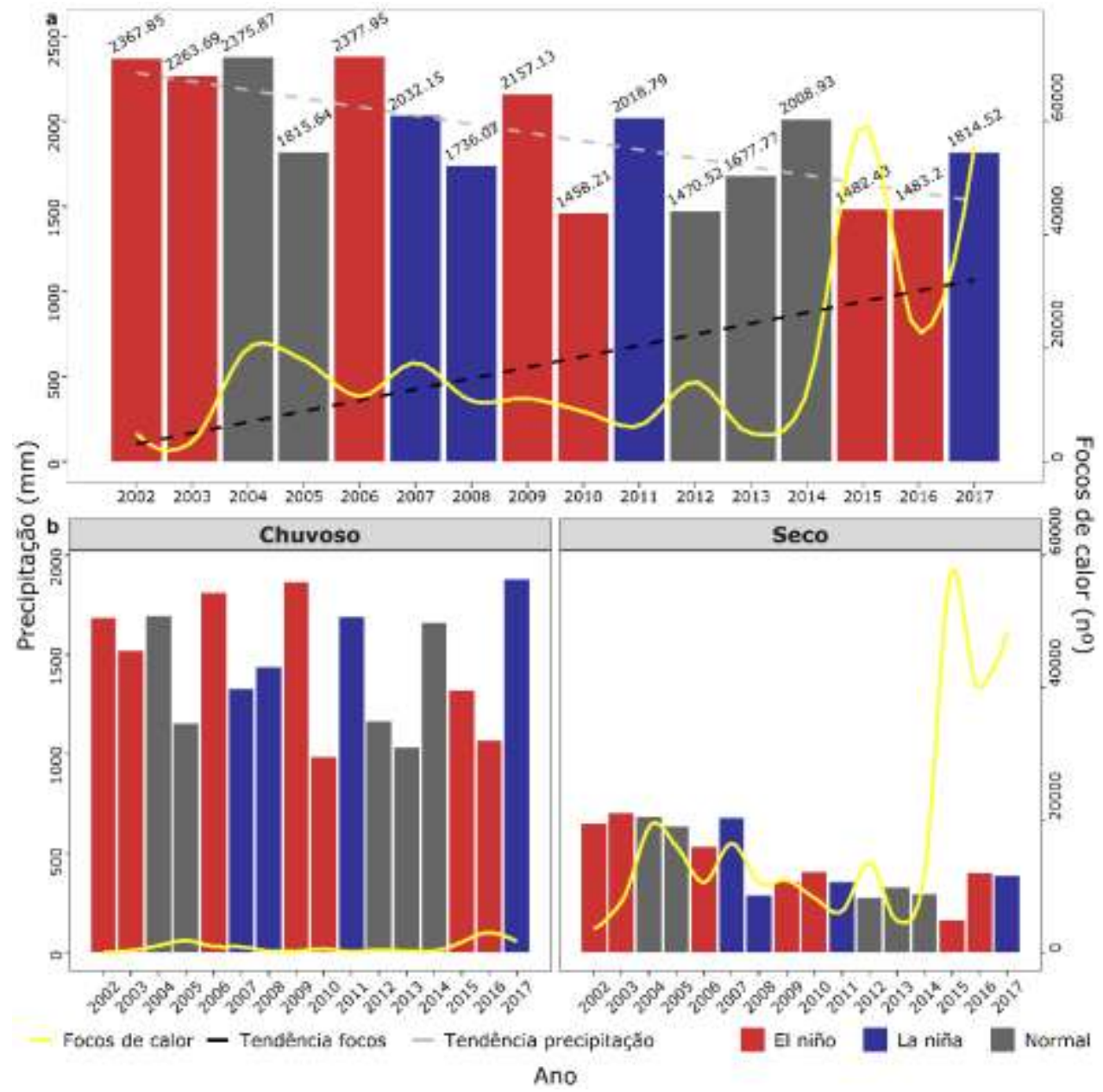


Figura 2 - Focos de calor e precipitação mensal da microrregião de Paragominas.

A análise da série histórica de focos, evidenciou a interação entre ocorrência dos focos e o período de regime pluviométrico. Na estação chuvosa, com uma precipitação média acumulada de $1.455 \mathrm{~mm}$, o número de focos representou apenas $4,86 \%$ do total de focos de queimadas registradas no período de análise, cerca de 13.656 ocorrências (Figura 2b). Já na estação seca, a média de precipitação acumulada foi de $445 \mathrm{~mm}$, o que propiciou a ocorrência de 267.111 focos, ou seja, 95,13\% dos focos contabilizados (Figura 2b), tornando evidente o efeito da sazonalidade climática, o que pode ser observado em todos os anos do período de análise (Figura 3).

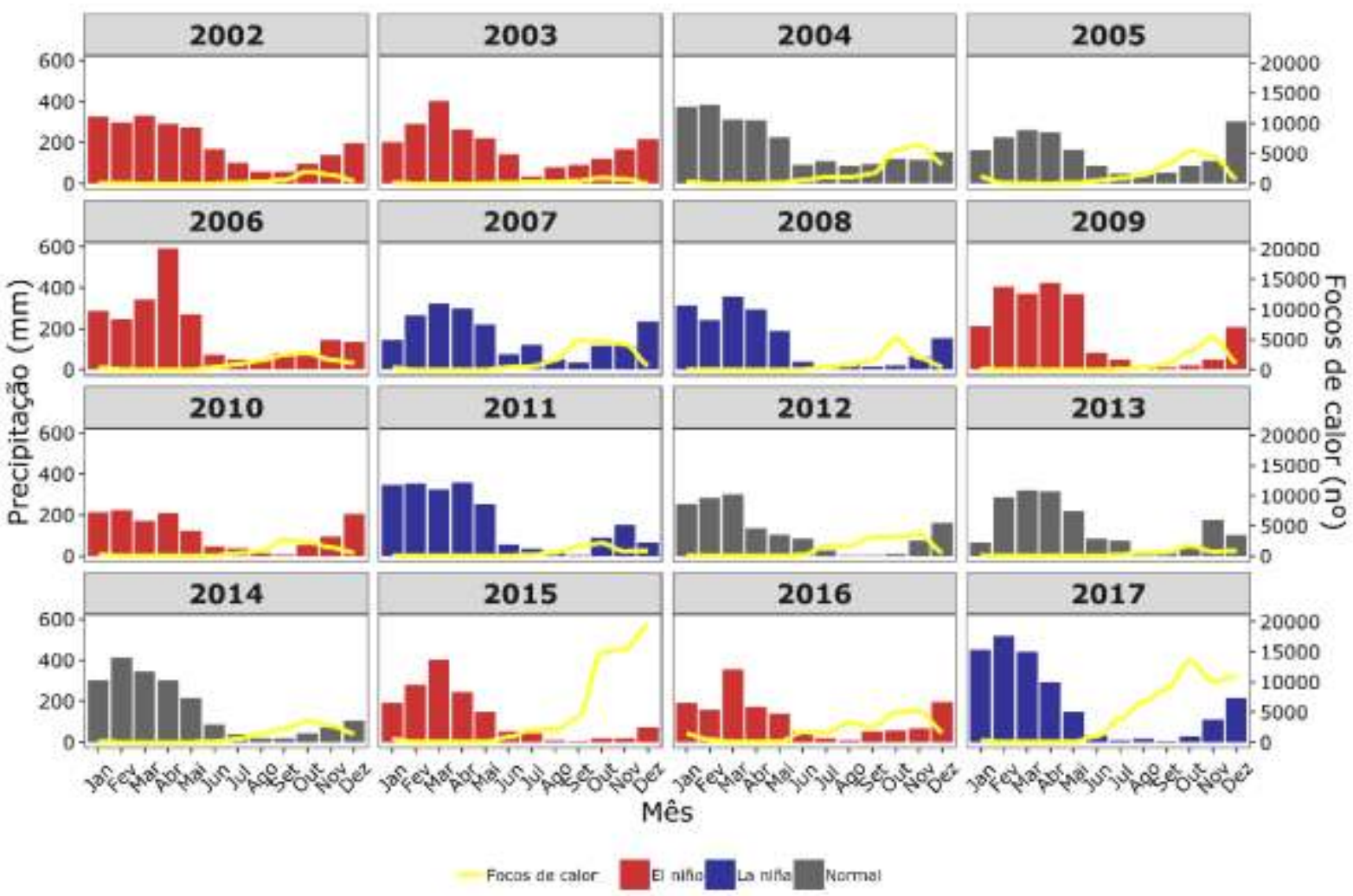

Figura 3 - Focos de calor e precipitação mensal da microrregião de Paragominas.

Já em relação aos fenômenos climáticos El Niño e La Niña, verificou-se que estes ocorreram com intensidade moderada, com exceção para os anos de 2015 e 2016, nos quais a intensidade do El Niño foi considerada forte. Contudo, apesar da baixa frequência de ocorrência no intervalo temporal de estudo, notase a influência deste fenômeno sobre o aumento dos registros de focos de calor para o ano de 2015 (Figura 3), impulsionado pelas reduções nos totais pluviométricos, computadas em períodos de El Niño de forte intensidade (MOREIRA et al., 2019).

Ao confrontar a série histórica de focos aos quantitativos de área de agricultura e de desmatamento, percebe-se que a tendência de crescimento do 
número de focos coincide com a expansão da fronteira agrícola na microrregião, assim como o desmatamento, contribuindo para o aumento de focos, principalmente entre os anos de 2002 a 2008 (Figura 4).

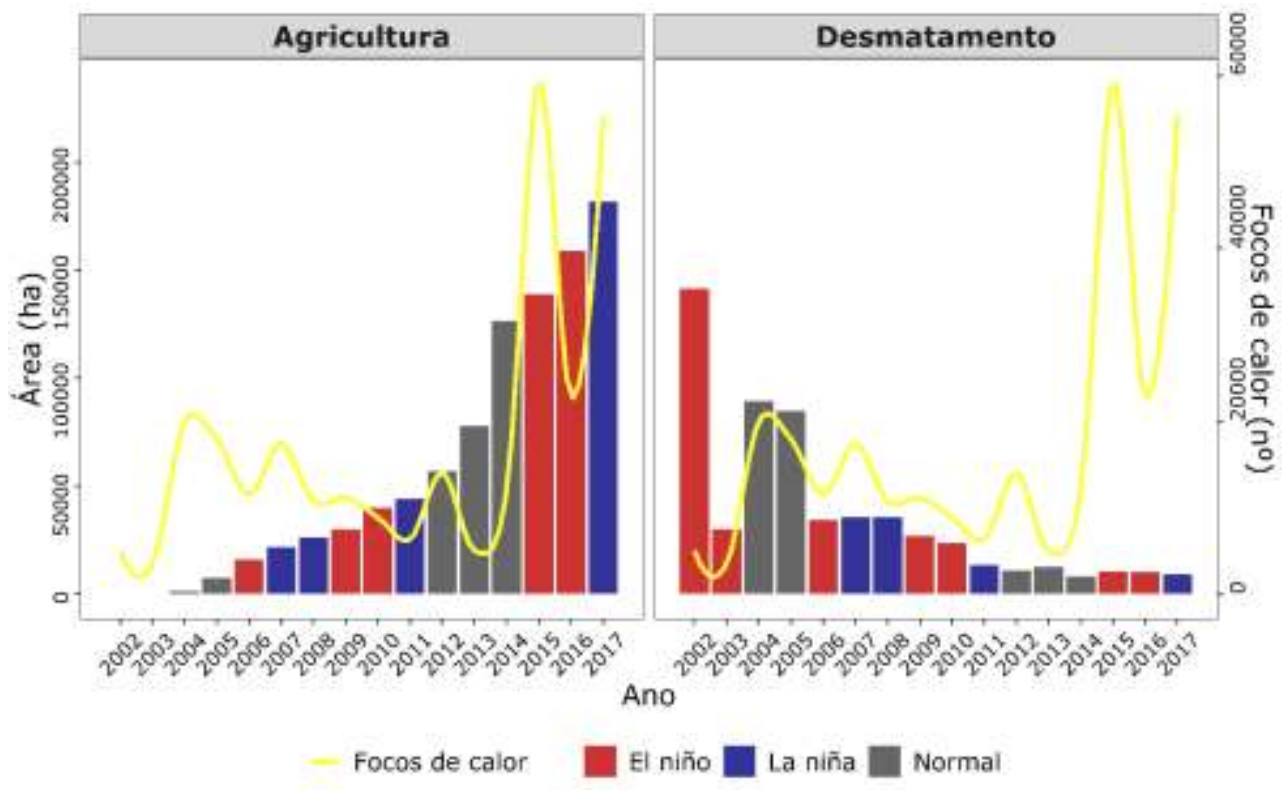

Figura 4 - Focos de calor e precipitação mensal da microrregião de Paragominas.

O crescimento das áreas destinadas a produção agrícola na microrregião, entre 2002 e 2017, apresentaram as maiores taxas de crescimento nos intervalos temporais de 2002 a 2006. Em contrapartida, as áreas desmatadas reduzem em aproximadamente $94 \%$ nos quinze anos de estudo, de tal modo que há aumento do desmatamento apenas nos intervalos de 2003-2004, 20062007, 2012-2013 e 2014-2015 (Tabela 3).

Tabela 3 - Áreas agrícolas e de desmatamento da microrregião de Paragominas.

\begin{tabular}{cccccc}
\hline \multirow{2}{*}{ Ano } & \multicolumn{2}{c}{ Área (ha) } & \multicolumn{3}{c}{ Taxa de crescimento (\%) } \\
\cline { 2 - 6 } & Agricultura & Desmatamento & $\begin{array}{c}\text { Intervalo } \\
\text { temporal }\end{array}$ & Agricultura & Desmatamento \\
\hline 2002 & 30,33 & 141471,96 & $2002-2003$ & 637,39 & $-78,80$ \\
2003 & 223,64 & 29985,72 & $2003-2004$ & 422,05 & 198,26 \\
2004 & 1167,50 & 89436,42 & $2004-2005$ & 540,03 & $-5,13$ \\
2005 & 7472,33 & 84848,61 & $2005-2006$ & 111,80 & $-59,50$ \\
2006 & 15826,19 & 34366,31 & $2006-2007$ & 36,94 & 3,57 \\
2007 & 21673,08 & 35593,55 & $2007-2008$ & 20,86 & $-0,59$ \\
2008 & 26194,51 & 35382,02 & $2008-2009$ & 13,62 & $-24,45$ \\
2009 & 29762,31 & 26730,65 & $2009-2010$ & 33,05 & $-11,75$ \\
2010 & 39597,91 & 23589,02 & $2010-2011$ & 10,89 & $-43,78$ \\
2011 & 43910,74 & 13261,41 & $2011-2012$ & 29,76 & $-17,85$ \\
2012 & 56977,74 & 10894,76 & $2012-2013$ & 36,74 & 15,50 \\
2013 & 77909,93 & 12583,26 & $2013-2014$ & 62,10 & $-36,10$ \\
2014 & 126290,82 & 8040,29 & $2014-2015$ & 9,96 & 27,34
\end{tabular}




\begin{tabular}{cccccc}
2015 & 138864,66 & 10238,35 & $2015-2016$ & 14,52 & $-1,50$ \\
2016 & 159032,82 & 10085,01 & $2016-2017$ & 14,28 & $-11,36$ \\
2017 & 181737,65 & 8939,33 & $2002-2017$ & 599131,76 & $-93,68$ \\
\hline
\end{tabular}

No ano de 2002 houve concentração de focos principalmente nos municípios de Bom Jesus do Tocantins; Dom Elizeu; Goianésia do Pará; Rondon do Pará e Ulianópolis, estando estes focos localizados próximos a áreas de desflorestamento (Figura 5a). Já a precipitação média anual foi considerada alta neste ano, com áreas de precipitação superiores a $2000 \mathrm{~mm}$, sendo este ano caracterizado por El Niño (Figura $5 \mathrm{~d}$ ).

Nesse ano, a extração madeireira era a principal renda dos municípios da microrregião, o que explica a grande área desmatada, bem como os focos de calor associados a estas, de tal maneira que 2002 foi um ano atípico, no qual há densidades alta e extrema dos focos de calor a sudoeste da microrregião, onde a precipitação foi alta. Contudo, como $98 \%$ dos focos de calor deste ano ocorreram no período seco, pode-se inferir que a média de $648 \mathrm{~mm}$ de chuva não foi suficiente para conter a ocorrência dos focos.

Em 2005 há concentração dos focos principalmente em Dom Elizeu, Paragominas e Ulianópolis (Figura $5 \mathrm{~b}$ ), os quais apresentaram os menores volumes de chuva, inferiores a $1700 \mathrm{~mm}$ (Figura 5e). Em contrapartida, nos municípios de Bom Jesus do Tocantins, Goianésia do Pará, e Rondon do Pará, as chuvas atingiram índices elevados, com registros superiores a $2000 \mathrm{~mm}$. Vale ressaltar que neste ano não houve influência do fenômeno ENOS (Figura 5e).

No ano de 2005 há uma redução de aproximadamente 40\% do desmatamento em relação a 2002, o que pode estar relacionado com o avanço da agricultura, gerando uma nova fonte de renda a microrregião. Neste ano há áreas com densidade alta e extrema de focos de calor a sudoeste da microrregião, contudo, a maior porção dessas concentrações se localizam na região central, no sentido Norte/Sul, onde estão registradas as menores áreas de precipitação. Ainda em 2005 foram evidenciadas manchas de desmatamento em todos os assentamentos da microrregião.

Para o ano de 2008 percebe-se uma redução do desmatamento, em consequência menor concentração dos focos de calor. Nota-se a expansão da fronteira agrícola no sentido Norte-Sul da microrregião, sendo essas áreas localizadas nos entornos das principais rodovias da microrregião (Figura 5c). Neste ano, apesar do fenômeno La Niña, mantém-se o cenário de baixos índices pluviométricos, nos municípios de Paragominas, Ulianópolis e Dom Elizeu (Figura 5f).

No ano de 2011, com a ocorrência do La Niña, observou-se um aumento da área com precipitação anual superior a $1700 \mathrm{~mm}$ (Figura $5 \mathrm{j}$ ), com concentração das chuvas em partes dos municípios de Goianésia do Pará; Rondon do Pará; Paragominas e Bom Jesus do Tocantins. No entanto, nas áreas destes municípios que apresentaram baixos índices pluviométricos, foi constatado focos de calor adensados. Há poucas áreas de desmatamento para este ano, contudo, percebe-se um incremento dos empreendimentos agrícolas no sentido Norte-Sul da microrregião (Figura $5 \mathrm{~g}$ ).

A redução dos focos de calor pode ter sido influenciada pelo sucesso da operação Arco de fogo (operação que visava combater o desmatamento ilegal na Amazônia), no ano de 2008, em consequência, a redução do desmatamento 
permitiu que em 2010, os municípios de Paragominas e Ulianópolis recebessem o selo de Município verde, enquanto que em 2011 os demais municípios da microrregião também obtiveram este selo, logo, a conscientização da população acerca do desmatamento, assim como a redução deste pode ter favorecido a baixa incidência dos focos de calor nestes anos (BARRETO; ARAÚJO, 2012; WHATELY; CAMPANILI, 2013).

Em 2014, não houve influência dos fenômenos climáticos ENOS, entretanto, nos municípios de Dom Elizeu; Paragominas; Rondon do Pará e Ulianópolis a pluviosidade foi menor em comparação com os outros municípios (Figura 5I), o que aliado com as áreas agrícolas desencadearam no maior agrupamento dos focos de calor nestes locais. O desmatamento deste ano aconteceu principalmente nos assentamentos localizados em Paragominas; Rondon do Pará e Ulianópolis (Figura 5h).

Vale ressaltar que neste ano, a microrregião foi a que mais produziu grãos no estado do Pará (FAPESPA, 2017), o que explica o incremento das áreas agrícolas. Além disso, as políticas de combate ao desmatamento aliados a moratória da soja, também favoreceram a redução das áreas desmatadas e o crescimento da agricultura (GIBBS et al., 2015; JUSYS, 2018).

Apesar do ano de 2017 ser caracterizado por La Niña, os resquícios do El Niño de intensidade forte de 2016 ocasionaram redução da precipitação média anual nas áreas de menor intensidade de precipitação (Marrom e laranja) (Figura 5m), assim, os focos foram mais dispersos pelos municípios da microrregião, estando estes concentrados nos entornos das áreas de agricultura dispostos no sentido Norte-Sul da microrregião (Figura 5i).

Ao longo destes quinze anos, os focos de calor se concentraram às margens das rodovias, sob influência do trânsito acentuado de veículos, bem como ao contexto da expansão territorial, pois com vistas no processo ocupacional e o escoamento da produção, durante o período imperial e início da república, as cidades cresceram nas margens das rodovias (AGUIAR et al., 2015). O que corrobora com os resultados encontrados no estudo de Costa; Bezerra; Oliveira (2017), que analisaram a influência da Rodovia BR-163 na incidência dos focos de calor, bem como Araújo et al. (2020), os quais avaliaram a influência da ação antrópica na incidência dos focos de calor na Microrregião de Paragominas, Estado do Pará, Norte do Brasil.

Além disso, os fenômenos climáticos ENOS apresentam influência sobre os focos de calor apenas quando ocorrem de intensidade forte, sendo a sazonalidade das chuvas um dos fatores associado a ocorrência dos focos de calor, de forma que as chuvas que ocorreram no período seco não foram suficientes para controla-los, pois as condições mais secas deste período favorecem o uso do fogo como forma de manejo do solo (ARAÚjo et al., 2020; PEREIRA; SILVA, 2016; VASCONCELOS et al., 2015). 


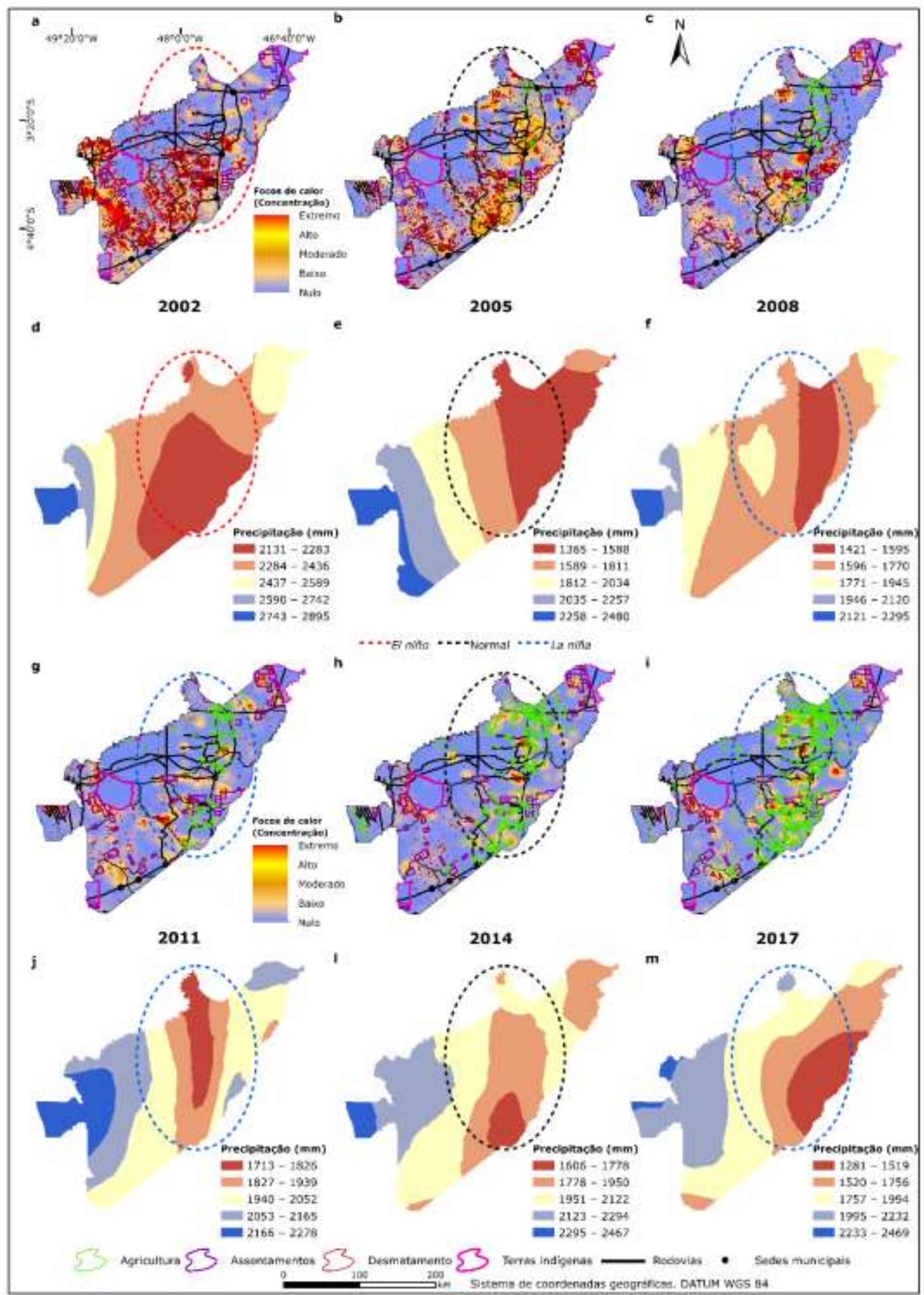

Figura 5 - Mapas de kernel e precipitação da microrregião de Paragominas.

A intensidade e duração da chuva influencia diretamente a ocorrência de focos de calor, de modo que a temperatura do ar é amenizada e há um 
acréscimo na umidade relativa do ar, tornando o material combustível menos propenso à combustão. Segundo Coelho Junior; Martins; Carvalho (2018), a temperatura é influenciada diretamente pela precipitação, da qual influi diretamente na combustão e propagação dos incêndios.

O efeito da precipitação sobre o potencial de propagação do fogo é mensurado de acordo com a uniformidade da umidade do material vegetal durante todo o ano, isto é possível quando em uma determinada região não é acometida por uma estação seca definida. Visto que, o potencial de ocorrência e propagação de incêndios é mitigado em regiões em que a estação chuvosa é concentrada em determinados meses e há longos períodos de estiagem durante outros. Como demonstrado na Figura 5 a região central da microrregião possui menores taxas pluviométricas, corroborando com a alta incidência de focos de calor nesta região.

De maneira geral, há um padrão espacial nas concentrações de focos de calor, onde áreas de densidade alta e extrema, estão presentes na porção central da área de estudo, nas mediações das rodovias, áreas desmatadas e de agricultura, bem como nos projetos de assentamentos. Esta concentração dos focos segue um arranjo espacial obedecendo a orientação Norte/Sul, em todos os anos analisados, exceto para o ano de 2002 onde as maiores concentrações estiveram presentes em áreas localizadas mais à sudoeste da microrregião, sendo estas concentrações decorrentes do desmatamento acentuado no município de Goianésia.

Apesar de não ser o fator principal na ocorrência dos focos de calor, a precipitação é determinante no padrão espacial destes, uma vez que na região central, com orientação Norte/Sul, estão as áreas de menor precipitação pluviométrica, ou seja, o posicionamento dos focos de calor está acondicionado em áreas de menor precipitação, portanto, o padrão espacial dos focos de calor está intimamente relacionado a precipitação.

Já o padrão temporal está relacionado aos fatores antrópicos, tais como desmatamento, expansão agrícola e agricultura familiar em assentamentos (ARAÚJO et al., 2020). Em áreas desmatadas, a conversão da vegetação em pastagem e/ou agricultura aumenta a temperatura do local, o que aliado ao uso do fogo neste processo de conversão ocasionam a incidência dos focos de calor.

Nas áreas de agricultura, a sua proximidade com as rodovias, a fim de prover o transporte de insumos e produção, aumenta o fluxo de veículos, consequentemente, a incidência e concentração de focos de calor (SANTOS; SOUZA; ARAÚJO, 2017). Adicionalmente, a agricultura anual possui um período de pousio, no qual o solo geralmente fica exposto, provocando um incremento da absorção de temperatura, o que gera focos de calor (GUTIÉRREZ-VELEZ et al., 2014). Tais fatores também foram observados nos estudos de IbarraMontoya; Huerta-Martínez (2016) e Marín et al. (2018), o que ratificam os resultados encontrados neste estudo.

Nos programas de assentamento, onde predomina a agricultura familiar, o fogo é uma prática cultural para abertura e preparo de área, por ser uma ferramenta eficaz e de baixo custo (SILVA et al., 2017). Além disso, a precariedade das estradas, a distância dessas comunidades, assim como a carência de crédito, assistência técnica, tecnologia e insumos, atrapalham a difusão e utilização de técnicas alternativas ao fogo (ex. Alley, Tritucap) 
(CARMENTA et al., 2016; DEVISSCHER et al., 2016; SAMPAIO; KATO; NASCIMENTO-E-SILVA, 2008).

Nas terras indígenas não houve concentração dos focos de calor, tampouco de áreas desmatadas, corroborando com os resultados de Araújo et al. (2020). Tal fato deve-se a cultura dessa população de aliar o uso da terra com a manutenção da biodiversidade, evitando a alteração e degradação das suas terras (BRITO; BARBOSA, 2015).

\section{CONCLUSÃO}

O padrão espacial dos focos de calor da microrregião de Paragominas é influenciado pela sazonalidade da precipitação, havendo uma maior concentração destes no centro da microrregião, sob orientação Norte/Sul, onde estão as áreas de menor precipitação. O padrão temporal e a intensidade dos focos de calor são influenciados pela ação antrópica, coincidindo com as áreas de menor precipitação, devido a associação do uso do fogo com o período de estiagem, bem como a agricultura anual.

Nos projetos de assentamento, deve-se intensificar as políticas públicas para garantir o acesso a técnicas alternativas ao sistema de corte e queima, a fim de mitigar os impactos do fogo ao meio ambiente, enquanto áreas agrícolas deveriam evitar o solo exposto durante o período de pousio. Tais medidas possibilitariam a redução da ocorrência dos focos de calor.

\section{REFERÊNCIAS BIBLIOGRÁFICAS}

ABREU, F. DE A.; SOUZA, J. DO S. A. Dinâmica espaço-temporal de focos de calor em duas terras indígenas do Estado de Mato Grosso: Uma abordagem geoespacial sobre a dinâmica do uso do fogo por Xavantes e Bororos. Floresta e Ambiente, v. 23, n. 1, p. 1-10, 2016.

AGUIAR, R. D. et al. Zoneamento De Risco De Incêndios Florestais No Parque Nacional Da Chapada Dos Veadeiros - Go. Enciclopédia Biosfera, v. 11, n. 21, p. 1943, 2015.

ALMEIDA, C. T. et al. Spatiotemporal rainfall and temperature trends throughout the Brazilian Legal Amazon, 1973-2013. International Journal of Climatology, $v$. 37, n. 4, p. 2013-2026, 2017.

ALVARES, C. A. et al. Köppen's climate classification map for Brazil. Meteorologische Zeitschrift, v. 22, n. 6, p. 711-728, 2013.

ARAÚJO, L. O. et al. Ação antrópica na incidência dos focos de calor na Microrregião de Paragominas, Estado do Pará, Norte do Brasil. Revista Brasileira de Gestão Ambiental e Sustentabilidade, v. 7, n. 17, p. 1153-1164, 2020.

BARRETO, P.; ARAúJO, E. O Brasil Atingirá sua Meta de Redução do Desmatamento ? Belém: Imazon, 2012. v. 1

BITTENCOURT, D. Z.; BAZZAN, T.; LAHM, R. A. Análise temporal e espacial dos focos de calor no município de São Francisco de Paula, RS , no período entre 2003 e 2012. Caderno de Estudos Geoambientais, v. 4, n. 1, p. 37-55, 2013.

BRITO, A. L. C. DE; BARBOSA, E. M. A gestão ambiental das terras indígenas e 
de seus recursos naturais: fundamentos jurídicos, limites e desafios. Veredas do Direito, v. 12, n. 24, p. 97-123, 2015.

CARMENTA, R. et al. Does the establishment of sustainable use reserves affect fire management in the humid tropics. PLoS ONE, v. 11, n. 2, p. 1-19, 2016.

CARVALHO, J. R. P. DE; ASSAD, E. D.; PINTO, H. S. Interpoladores geoestatísticos na análise da distribuição espacial da precipitação anual e de sua relação com altitude. Pesquisa Agropecuaria Brasileira, v. 47, n. 9, p. 1235$1242,2012$.

CARVALHO, M. F. O. DE; CARDOSO, M. F.; ALMEIDA, B. N. DE. Estimativa do risco de incêncios florestais com base em fitofisionomias e fatores climáticos. Biodiversidade Brasileira, v. 6, n. 2, p. 187-204, 2016.

CAÚLA, R. H. et al. Overview of fire foci causes and locations in Brazil based on meteorological satellite data from 1998 to 2011. Environmental Earth Sciences, v. 74, n. 2, p. 1497-1508, 2015.

CAÚLA, R. H. et al. Nonparametric Statistics Applied to Fire Foci Obtained by Meteorological Satellites and Their Relationship to the MCD12Q1 Product in the State of Rio de Janeiro, Southeast Brazil. Land Degradation and Development, v. 28, n. 3, p. 1056-1067, 2017.

CLEMENTE, S. DOS S.; OLIVEIRA JÚNIOR, J. F. DE; LOUZADA, M. A. P. Focos de calor do bioma Mata Atântica no estado do Rio de Janeiro: uma abordagem de gestão e legislação ambiental. Revista de Ciências Agroambientais, v. 15, n. 2, p. 158-174, 2017.

COELHO JUNIOR, L. M.; MARTINS, K. DE L. DA C.; CARVALHO, M. Carbon Footprint Associated with Firewood Consumption in Northeast Brazil: An Analysis by the IPCC 2013 GWP 100y Criterion. Waste and Biomass Valorization, v. 10, n. 10, p. 2985-2993, 2018.

COSTA, A. M. S. DA; BEZERRA, P. E. S.; OliveirA, R. S. DE. Mudanças no uso e ocupação da terra associadas a focos de calor na área de in- fluência da Rodovia BR-163 ( Cuiabá-Santarém ). Revista Brasileira de Gestão Ambiental, v. 11, n. 1, p. 119-125, 2017.

DEPPE, F. et al. Comparação de índice de risco de incêndio florestal com focos de calor no estado do Paraná. Floresta, v. 34, n. 2, p. 119-126, 2004.

DEVISSCHER, $T$. et al. Increased wildfire risk driven by climate and development interactions in the Bolivian Chiquitania, Southern Amazonia. PLoS ONE, v. 11, n. 9, p. 1-29, 2016.

ECMWF - EUROPEAN CENTRE FOR MEDIUM-RANGE WEATHER FORECASTS. Forecasts Datasets. Disponível em: <https://www.ecmwf.int/>. Acesso em: 8 maio. 2020.

FAPESPA, F. A. DE A. A E. E P. DO P. Boletim Agropecuário do Estado do Pará 2015BelémFAPESPA, , 2017.

FERNANDES, M. DO C. et al. Avaliação Geoecológica de Susceptibilidade à Ocorrência de Incêndios no Estado do Rio de Janeiro, Brasil. Floresta e Ambiente, v. 18, n. 3, p. 299-309, 2011.

GIBBS, H. K. et al. Brazil's Soy Moratorium. Science, v. 347, n. 6220, p. 377- 
$378,2015$.

GOIS, G. DE et al. EVI2 index trend applied to the vegetation of the state of Rio de Janeiro based on non-parametric tests and Markov chain. Bioscience Journal, v. 32, n. 4, p. 1049-1058, 2016.

GUTIÉRREZ-VELEZ, V. $\mathrm{H}$. et al. Land cover change interacts with drought severity to change fire regimes in Western Amazonia. Ecological Applications, v. 24, n. 6, p. 1323-1340, 2014.

IBARRA-MONTOYA, J. L.; HUERTA-MARTÍNEZ, F. M. Modelado espacial de incendios: una herramienta predictiva para el Bosque La Primavera, Jalisco México. Revista Ambiente e Agua, v. 11, n. 1, p. 35-49, 2016.

INPE - INSTITUTO NACIONAL DE PESQUISAS ESPACIAIS. PRODES Monitoramento de Floresta Amazônica por Satélite. Disponível em: <http://www.obt.inpe.br/OBT/assuntos/programas/amazonia/prodes>. Acesso em: 14 abr. 2019.

INPE - INSTITUTO NACIONAL DE PESQUISAS ESPACIAIS. Portal do Monitoramento de Queimadas e Incêndios. Disponível em: <http://www.inpe.br/queimadas>. Acesso em: 20 mar. 2020a.

INPE - INSTITUTO NACIONAL DE PESQUISAS ESPACIAIS. Programa Queimadas. Disponível em: <http://queimadas.dgi.inpe.br//queimadas/portal>. Acesso em: 16 fev. 2020b.

JUSYS, T. Changing patterns in deforestation avoidance by different protection types in the Brazilian Amazon. PLoS ONE, v. 13, n. 4, p. 1-16, 2018.

LARCHER, W. Ecofisiologia Vegetal. Rima ed. São Carlos: [s.n.].

LOPES, A. C. L. et al. Análise da distribuição de focos de calor no município de Novo Progresso, Pará. Revista Verde de Agroecologia e Desenvolvimento Sustentável, v. 12, n. 2, p. 298, 2017.

MACHADO, R. L. et al. Spatial variability of maximum annual daily rain under different return periods at the Rio de Janeiro state, Brazil. Bragantia, v. 69, n. suppl, p. 77-84, 2010.

MAPBIOMAS DEVELOPMENT TEAM. Coleções MAPBIOMAS. Disponível em: $<$ https://mapbiomas.org/colecoes-mapbiomas-1?cama_set_language=pt-BR>. Acesso em: 16 fev. 2019.

MARÍN, P. et al. Drought and Spatiotemporal Variability of Forest Fires Across Mexico. Chinese Geographical Science, v. 27, n. 6, p. 1-13, 2018.

MOREIRA, S. DE F. et al. A Influência dos fenômenos El Niño e La Niña sobre a dinâmica climática da região Amazônica. Multidisciplinary Reviews, v. 1, p. 1-7, 2019.

NASCIMENTO, O. DOS S. et al. Análise espaço-temporal dos focos de calor no município de Parnaguá Piauí, entre 2008 a 2015. Revista Brasileira de Gestão Ambiental, v. 11, n. 1, p. 193-199, 2017.

NEPSTAD, D. C. et al. Mortality of large trees and lianas following experimental drought in an Amazon forest. Ecology, v. 88, n. 9, p. 2259-2269, 2007.

NUNES, J. R. S.; SOARES, R. V.; BATISTA, A. C. Análise Da Fórmula De Monte 
Alegre Alterada (Fma+) Para O Estado Do Paraná. Floresta, v. 37, n. 1, p. 1-14, 2007.

OLIVEIRA, U. C.; DE OLIVEIRA, P. S. Mapas de Kernel como Subsídio à Gestão Ambiental: Análise dos Focos de Calor na Bacia Hidrográfica do Rio Acaraú, Ceará, nos Anos 2010 a 2015. Espaço Aberto, v. 7, n. 1, p. 87-99, 2017.

PENA, H. W. A.; OLIVEIRA, F. DE A.; CAMPOS, P. S. DA S. Análise multivariada e identificação dos padrões de desflorestamento no estado do Pará-AmazôniaBrasil, 2000 á 2009. Contribuciones a las Ciencias Sociales, v. 13, p. 1-15, 2011.

PEREIRA, J. A. V.; SILVA, J. B. DA. Detecção De Focos De Calor No Estado Da Paraíba: Um Estudo Sobre As Queimadas. Revista Geográfica Acadêmica, v. 10, n. 1, p. 5-16, 2016.

QGIS DEVELOPMENT TEAM. QGIS versão 2.18 Las Palmas, 2016.

SAMPAIO, C. A.; KATO, O. R.; NASCIMENTO-E-SILVA, D. Sistema De Corte E Trituração Da Capoeira Sem Queima Como Alternativa De Uso Da Terra, Rumo à Sustentabilidade Florestal No Nordeste Paraense. Revista de Gestão Social e Ambiental, v. 2, n. 1, p. 41-53, 2008.

SANTOS, B. A. et al. Distribuição espaço-temporal dos focos de calor no estado de Minas Gerais. Anuario do Instituto de Geociencias, v. 42, n. 3, p. 64-84, 2019.

SANTOS, T. N. DE O.; SOUZA, E. L.; ARAÚJO, M. F. A reinvenção do agronegócio no sudeste paraense: uma análise do avanço da soja e sua relação com a sustentabilidade. Revista de gestão do Agronegócio da UNIPAMPA, v. 2, n. 2, p. 177-190, 2017.

SILVA, M. N. DA et al. A seca no Maranhão no período de 2010 a 2016 e seus impactos. Parcerias Estratégicas, v. 22, n. 44, p. 119-138, 2017.

SOUZA, E. B.; AMBRIZZI, T. Pentad Precipitation Climatology over Brazil and The Associated Atmospheric Mechanisms. Revista Climanálise, v. 6, n. 5, p. 3644, 2003.

SYPHARD, A. D.; KEELEY, J. E.; BRENNAN, T. J. Comparing the role of fuel breaks across southern California national forests. Forest Ecology and Management, v. 261, n. 11, p. 2038-2048, 2011.

THOMPSON, M. P. et al. Integrated national-scale assessment of wildfire risk to human and ecological values. Stochastic Environmental Research and Risk Assessment, v. 25, n. 6, p. 761-780, 2011.

TOMZHINSKI, G. W. T.; COURA, P. H. F.; FERNANDES, M. DO C. Avaliação Da Detecção De Focos De Calor Por Sensoriamento Remoto Para O Parque Nacional Do Itatiaia. Biodiversidade Brasileira, v. Ano I, n. 2, p. 201-2011, 2011.

TONINI, M. et al. Evolution of forest fires in Portugal: from spatio- temporal point events to smoothed density maps. Nat Hazards, v. 85, p. 1489-1510, 2016.

TORRES, F. T. P. et al. Correlações entre os elementos meteorológicos e as ocorrências de incêndios florestais na área urbana de Juiz de Fora, MG. Revista Arvore, v. 35, n. 1, p. 143-150, 2011. 
VASCONCELOS, S. S. DE et al. Suscetibilidade da Vegetação ao fogo no sul do Amazonas sob condições meteorológicas atípicas durante a seca de 2005. Revista Brasileira de Meteorologia, v. 30, n. 2, p. 134-144, 2015.

WHATELY, M.; CAMPANILI, M. Programa Municípios Verdes: lições aprendidas e desafios para 2013/2014. 1. ed. Belém: Governo do Pará, 2013. 